\title{
Correlations Between Tree Thinking and Acceptance of Evolution in Introductory Biology Students
}

\author{
J Phil Gibson ${ }^{1,2^{*}}$ and Mariëlle H Hoefnagels ${ }^{1,2}$
}

\begin{abstract}
Background: Tree thinking refers to an approach to evolution education that emphasizes reading and interpreting phylogenetic trees. We studied the relationship between introductory biology students' tree-thinking ability and their acceptance of evolutionary theory.

Results: Comparisons between a semester in which interpretation of phylogenetic trees and related concepts were taught as stand-alone topics versus one in which tree thinking was used as an organizing framework for the course curriculum found significant increases in students' ability to read and interpret trees in both semesters, but only in the tree thinking semester was there a significant increase in students'scores on the Measure of the Acceptance of the Theory of Evolution (MATE) instrument. Over four additional semesters, the Tree Thinking Concept Inventory (TTCI) was used to assess students' tree-thinking abilities before and after the course. We found that MATE posttest scores correlated with gains in tree-thinking ability. These increases in MATE posttest scores were predominantly due to students' reporting greater acceptance of the scientific evidence supporting evolutionary theory.

Conclusions: Increased acceptance of evolution in a tree-thinking versus non-tree-thinking semester and significant positive correlations between TTCl and MATE scores indicate there is a relationship between tree-thinking ability and acceptance of evolution. This result suggests that, as a framework to connect different forms of data and investigate a variety of biological phenomena, tree thinking can promote greater acceptance of the evidence and scientific validity of evolutionary theory in introductory biology students.
\end{abstract}

Keywords: Evolution, Macroevolution, Phylogeny, Tree thinking, Undergraduate

\section{Background}

Surveys consistently report low levels of understanding and acceptance of evolution in the United States (Miller et al. 2006). Far from being a feature of the general public alone, many undergraduates enter introductory biology courses with minimal understanding of and numerous misconceptions about evolution and its relationship to other biological principles (Johnson and Peeples 1987; Sundberg 1997; Dagher and BouJaoude 1997; Bishop and Anderson 1990; Meir et al. 2007; Nehm and Reilly 2007). This lack of understanding has been shown to often

\footnotetext{
*Correspondence: jpgibson@ou.edu

2 Department of Microbiology and Plant Biology, University of Oklahoma,

Norman, OK 73019, USA

Full list of author information is available at the end of the article
}

continue throughout undergraduate education and even into graduate school (Alters and Nelson 2002; Nehm and Reilly 2007; Gregory and Ellis 2009 Losos et al. 2013).

Insufficient instruction by high school biology teachers who may accept evolution but hold misconceptions about it or limit coverage to avoid conflicts; teachers who do not accept the scientific validity of evolution, question the existence of evidence supporting evolution, or doubt its acceptance by scientists; and teachers who continue to present non-scientific explanations as equivalent if not superior "alternatives" to biological evolution have been identified as causes of low understanding and acceptance of evolution in high school graduates (National Academy of Sciences 1999, 2008; Rutledge and Mitchell 2002: Miller 2005; Moore and Kraemer 2005; Verhey 2005; 
Berkman et al. 2008; Cavallo and McCall 2008; Moore 2008; Moore and Cotner 2009a, b; Smith 2010; Berkman and Plutzer 2011; Moore et al. 2011; Lloyd-Strovas and Bernal 2012). In a recent study, Yates and Marek (2014) found that students in some high school biology classes started the course with a more accurate understanding of evolution than their teachers, but left those courses with less understanding of and more misconceptions about evolution than they had when they entered.

Unfortunately, challenges in evolution education do not end once students enter college and university introductory biology courses. Because evolution is built upon a synthesis of data from scientific fields ranging from molecular genetics to paleontology, presenting the sheer breadth of this information in only a few introductory biology lectures can potentially overwhelm students and cause them to consider evolution as just one of the many separate topics covered during the semester rather than a unifying principle of biology (National Research Council 2012). Furthermore, it has been suggested that overemphasis on microevolution in introductory courses and insufficient coverage of other essential facets of evolutionary theory such as speciation, ancestor-descendant relationships, biogeography, and extinction (Catley 2006; Catley and Novick 2009; Smith 2010), as well as inconsistent and potentially confusing presentation of evolution in textbooks (Linhart 1997) can also prevent introductory students from developing a complete understanding of evolutionary theory (Lloyd-Strovas and Bernal 2012; Hobbs et al. 2013).

When investigating the effect of any curricular activity in science education in general and evolution education in particular, it is important to be mindful of the relationships and distinctions among knowledge, belief, and acceptance. Knowledge and belief are separate constructs that influence teaching and learning about evolution (Smith and Siegel 2004; Alters 2005). Beliefs are highly subjective, based on personal experience, and resistant to contrary evidence, so they are typically resistant to change (Sinatra et al. 2008). Likewise, beliefs are not subject to the same empirical criteria as scientific evidence (Southerland et al. 2001). Consequently, changing students' beliefs may not be an appropriate objective in evolution education. Indeed, changing beliefs about evolution is difficult (Demastes-Southerland et al. 1995; Nadelson and Southerland 2010). Therefore, rather than attempting to change beliefs a more appropriate objective is increasing students' acceptance of evolutionary theory (Smith and Siegel 2004). Acceptance indicates an understanding of the scientific evidence, critical evaluation of empirical evidence and the methods used to gather and analyze it, and a scientifically logical interpretation of how that evidence fits into the larger framework of scientific theory (Rutledge and Mitchell 2002; Nadelson and Southerland 2010).

One curricular change that has been suggested to improve evolution education and promote greater acceptance of evolution, particularly at the introductory level, is to increase emphasis on phylogenetic tree thinking. The concept of tree thinking encompasses the skills and knowledge necessary to correctly interpret and understand the information about evolutionary relationships, patterns, and processes contained in phylogenetic trees (Baum et al. 2005; Baum and Offner 2008; Baum and Smith 2013). Ever since Darwin first used a branching tree diagram to represent his initial conceptions of nested, evolutionary diversification of lineages from a common ancestor in his Notebook B and later as the only figure in The Origin of Species (Darwin 1859), phylogenetic trees have become the primary diagrammatic representation of broad-scale evolution that guides research and thought throughout biology (Baum and Smith 2013). It has been suggested that greater inclusion of tree thinking in biology courses will not only increase students' skills in phylogenetics, a topic that has historically received less attention at the introductory level than others, but it can also serve as a platform to improve their broader understanding and acceptance of evolutionary theory (O'Hara 1997; Baum et al. 2005; Catley 2006; Gregory 2008; Catley and Novick 2009; Kalinowski et al. 2010; Smith 2010).

Correctly applying tree thinking to interpret phylogenetic trees requires technical knowledge of the diagrams and an understanding of fundamental biological and evolutionary principles they represent (Donovan 2005; Baum and Offner 2008). Consequently, mistakes reading phylogenetic trees can give insights into student misconceptions about different aspects of evolution and evolutionary theory (Baum et al. 2005; Crisp and Cook 2005; Meir et al. 2007; Meisel 2010). For example, determining relationships by using branch tip proximity (i.e., "reading across the tips") or the number of nodes between lineages (i.e., "node counting") not only signify deficient skills in how to read a tree, but also a fundamental misunderstanding of the concept of common ancestry that is the core of evolutionary theory. In addition to providing a diagnostic tool to identify students' misconceptions about evolution, tree thinking can also serve as an organizing concept that connects different forms of data that serve as evidence of evolution. Thus, there are reasons to suspect that improved tree thinking might foster greater acceptance of evolution in undergraduates (Alters and Nelson 2002; Nehm et al. 2009; Halverson 2011).

A number of individual activities have been developed to teach tree thinking and improve acceptance of evolution (Gendron 2000; Goldsmith 2003; Perry et al. 2008; 
Smith and Cheruvelil 2009; Halverson 2010; Gibson and Cooper 2014). Prior studies have failed to show convincingly that completing a single tree-thinking activity increases students' acceptance of evolution and have not yielded uniform conclusions (Southerland and Sinatra 2005; Lloyd-Strovas and Bernal 2012). Larger curricular modifications that infuse tree thinking throughout a course may be necessary to significantly change acceptance of evolutionary theory. Indeed, significant increases in acceptance of evolution were found when tree thinking was emphasized throughout upper level biology courses (Nadelson and Southerland 2010: Dodick and Orion 2002; Catley and Novick 2009). While this is encouraging, the effect of including tree thinking on introductory-level students' acceptance of evolution has not been thoroughly explored.

In this study, we investigated the relationship between introductory biology students' tree-thinking skills and their acceptance of evolution to determine whether using tree thinking as an organizing framework throughout an introductory-level course can improve students' acceptance of evolution as a valid, scientific theory that unifies a diverse array of empirical evidence and provides a foundation for all areas of biology. Thus, the tree thinking framework we are investigating can be summarized as embodying the classic statement by Dobzhansky (1973) that, "Nothing in biology makes sense except in the light of evolution," and its two more recent logical extensions that "Nothing in evolution makes sense except in the light of phylogeny" (Society of Systematic Biologists 2001) and "Nothing in evolution makes sense except in the light of DNA" (Kalinowski et al. 2010).

\section{Methods}

\section{Course and Study Participants}

The study focused on BIOL 1134 Evolution, Ecology, and Diversity. It is one of two introductory-level courses required for biology, plant biology, and microbiology majors and serves as a general education science course for non-majors. The course objective is to introduce students to biological diversity, the evolutionary processes that produce biological diversity, and the basic features of structure and function in biological systems at the organismal and ecological levels. The course includes a single lecture (taught by JPG) and weekly laboratory sessions (taught by graduate teaching assistants). Participants were recruited on the first day of class each semester and provided a participant consent form to opt-in for participation in the study in accordance with IRB approved and mandated procedures. Background information about major, year in college, and whether they had previously completed college or university introductory biology courses that covered evolution was also collected from each student.

Because only one section of BIOL 1134 is offered each semester, it was not possible to compare non-tree-thinking and tree-thinking curricula in concurrent sections. Thus, in our initial study, we compared a section of BIOL 1134 offered in Fall 2009 (designated F09) that covered phylogenetics but did not emphasize tree thinking with a section offered in Spring 2010 (designated S10) that used a tree-thinking framework throughout the course. The same general topics were covered in both semesters, and both used case studies, guided inquiry, and active learning activities. However, the S10 tree thinking section included additional activities that involved phylogenetic analysis or interpretation. Most of the content that was cut from lecture to allow greater coverage of tree thinking was accommodated in laboratory sessions. Due to human subjects research guidelines, only the tree-thinking curriculum was used in the final four semesters of the study from spring semester 2011 through fall semester 2012 (designated S11, F11, S12, and F12, respectively). However, by using multiple linear regression analysis to look for correlations between the extent to which individual students improved their tree thinking and their acceptance level, we were able to more accurately assess whether improved teaching tree thinking also raises acceptance of evolution.

\section{Tree-Thinking Curriculum Structure}

At the broad scale, evolution is a process of nested descent with modification, with lineages diverging from common ancestors and producing the branching patterns of phylogenetic trees. The tree-thinking curriculum we are studying emphasizes integrating concepts of inheritance, microevolution, macroevolution, and trait diversification to help students understand the many ways in which DNA and other forms of data corroborate one another across different hierarchical levels and support evolutionary theory. Because tree thinking depends on understanding common ancestry and descent, there was deliberate emphasis on how successful reproduction and inheritance of genetic variation among many individuals and across generations are represented in phylogenetic trees. These themes showed up repeatedly in many topics covered in the course (e.g., floral adaptations, host-parasite interactions, Hox genes, animal diversity, etc.). The goal was to draw close connections from such fundamental concepts as Mendelian inheritance and pedigrees to the more complex topics of phylogenetics and tree thinking. This approach emphasizes evolution as an emergent property of biological systems operating from the molecular to the ecosystem levels of organization. 
Active learning exercises were employed in lecture throughout the course in all semesters. Case studies and problem sets explored the following topics: inheritance, pedigree analysis, and population genetics (AronovaTiuntseva and Herreid 2003; Leander and Huskey 2008; Rice 2010); natural selection (Evarts et al. 2006; Gibson 2008; Horvath 2009a); phylogeny construction and interpretation (Horvath 2009b); and trait evolution (Herreid 2005; Flammer 2007). Laboratory sessions paralleled lecture topics. In lab, students used guided inquiry activities to learn and apply tree thinking in several different modules. Basic principles and process of phylogenetic analyses were studied using the Great Clade Race (Goldsmith 2003) and a modification of the Dendrogrammaceae phylogenetic construction activity (Duncan et al. 1980). Students applied their knowledge of phylogenetic data collection and analysis through activities that investigated plant and animal diversity (Smith and Cheruvelil 2009; Gibson and Cooper 2014). These involved students collecting morphological data from representative specimens of different taxa and then using their data to construct trees with the phylogenetic analysis program Mesquite (Mesquite Project Team 2009). Next, students constructed phylogenies using genetic data (e.g., $r b c L$ or mitochondrial gene sequences) for comparison to their structural tree. These activities not only gave students opportunities to develop phylogenetic analysis skills, but also provided multiple opportunities to apply tree thinking using different forms of data so they could engage in the scientific processes biologists use to investigate evolution questions. Resources for specific activities and sample syllabi are available at http://www.ou.edu/gibsonlab/Tree_Thinking/Tree_Thinking.html.

\section{Assessment}

All students in the course were given the opportunity to complete the assessment instruments for a small number of points, but only data from students who self-selected to participate and completed all pretest and posttest assessments were included in the analysis.

In initial study comparing students between the nontree thinking (F09) and tree thinking (S10) semesters, students' overall ability to read and interpret phylogenetic trees was evaluated using a subset of questions from the Understanding Evolutionary Trees Worksheet (UET, Additional file 1), a general tree thinking assessment instrument developed by Meir et al. (2007) that includes multiple choice questions about phylogenetic trees and questions asking students to construct a simple phylogeny from provided data.

Although data from the UET assessment are informative, aspects of the wording in distractors and limited topic coverage were found to present confounding factors that limited detailed analysis of results. Consequently, we replaced the UET instrument with a subset of 14 multiple-choice questions from Naegle's (2009) Tree Thinking Concept Inventory (TTCI, Additional file 2) in the S11, F11, S12, and F12 semesters. The TTCI instrument supports more detailed exploration of specific aspects of students' ability to describe basic features of trees, read phylogenetic trees to determine relationships, and interpret the evolutionary information contained in them. Distractors in the TTCI included common misconceptions about time, common ancestry, trait evolution, and evolutionary processes. The TTCI also asks students to report whether they have previously seen or learned to read phylogenetic tree diagrams. The TTCI was administered as a pretest $\left(\mathrm{TTCI}_{\mathrm{PRE}}\right)$ and posttest $\left(\mathrm{TTCI}_{\mathrm{POST}}\right)$.

Acceptance of evolution was assessed in all six semesters using the Measure of Acceptance of the Theory of Evolution (MATE) instrument (Rutledge and Warden, 1997; Rutledge and Sadler 2007), administered as both a pretest $\left(\mathrm{MATE}_{\mathrm{PRE}}\right)$ and a posttest $\left(\mathrm{MATE}_{\mathrm{POST}}\right)$. The MATE is a 20-question, five-point Likert-scale instrument that asks respondents the extent to which they agree or disagree with statements about the process, the evidence for, and the scientific validity of evolutionary theory. Statements are paired for each topic with a positive and negative phrasing. For example statement M16, (Evolutionary theory is supported by factual, historical, and laboratory data.) and statement M4 (The theory of evolution is based on speculation and not valid scientific observation and testing.) address the same topic (Basis of evolutionary theory in scientific data) with a positive and negative phrasing, respectively.

\section{Data Analysis}

To evaluate tree-thinking ability, the frequencies of different misconception and deficient skills were summarized and compared between pretest and posttest responses from the UET assessment administered in F09 and S10. Mean score between the UET pretest and posttest were compared through Paired Samples $t$ tests. For the TTCI data, mean and standard deviation (SD) were calculated for the $\mathrm{TTCI}_{\mathrm{PRE}}$ and $\mathrm{TTCI}_{\mathrm{POST}}$ scores within the S11, F11, S12, and F12 semesters and for data pooled across semesters. Mean $\mathrm{TTCI}_{\mathrm{PRE}}$ and $\mathrm{TTCI}_{\mathrm{POST}}$ scores were then compared within pretests and posttests via ANOVA or Paired Samples $t$ tests. The TTCI $\mathrm{PRE}_{\text {and }}$ TTCI $\mathrm{POST}_{\mathrm{P}}$ scores were compared by Paired Samples $t$ tests. All data were analyzed using PASW Statistics (version 18.0).

Because scaled ordinal data from Likert responses in the MATE instrument violate assumptions of parametric statistical techniques (Huck 2008), range, median (Mdn), and quartiles were calculated for MATE $\mathrm{PRE}_{\text {and MATE- }}$ POST in all semesters. Within pretests and posttests, 
median values of $\mathrm{MATE}_{\mathrm{PRE}}$ and MATE $\mathrm{POST}_{\mathrm{PO}}$ were compared via Kruskal-Wallis tests and Mann-Whitney U tests. MATE pretest and posttest scores for individual semesters and pooled data across semesters were compared through a non-parametric Related-Samples Wilcoxon Signed Ranks Test (Sokal and Rohlf 2012).

\section{Normalized change, $c$, was calculated as}

$c=($ Posttest score - Pretest score $) /(100-$ Pretest score $)$

to compare the difference between the pre and post-test scores relative to the maximum possible gain in posttest score(Marx and Cummings 2007). This statistic was calculated for UET scores $\left(c_{U}\right)$ in F09 and S10, TTCI scores $\left(c_{T}\right)$ in S11 through F12, and MATE scores $\left(c_{M}\right)$ in all semesters to quantify individual student learning gains. Patterns of correct and incorrect answers to each question in the TTCI were further evaluated through Item Analysis to calculate the Discrimination Index $(D)$ that quantifies the difference in percentage of correct responses between the upper $27 \%\left(U_{27} \%\right)$ and lower $27 \%\left(L_{27 \%}\right)$ of TTCI scores (Hopkins and Stanley 1981). Responses were also compared between the $U_{27} \%$ and $L_{27 \%}$ of MATE scores, but because there are no correct or incorrect responses, $D$ was not calculated.

Students enrolled in a particular semester do not represent a random sampling of potential participants. Because it is not possible to randomly assign students to control and treatment groups, evaluating of the effect of a tree-thinking versus non-tree-thinking curriculum is best achieved through comparisons of MATE $_{\text {PRE }}$ and MATE $_{\text {POST }}$ scores within semesters. To do this, a student-level, multiple linear regression model was used to investigate the relationship between tree thinking and acceptance of evolution in semesters S11, F11, S12, and F12 (Theobald and Freeman 2014). Instead of comparing "control' and "treatment" semesters, multiple linear regression analysis accounts for various non-random factors such as previous introductory biology coursework or preexisting differences in ability to read phylogenetic trees that can affect acceptance of evolution,. In particular, the pretest MATE and TTCI values serve as controls in linear regression analysis of posttest scores making it possible to evaluate the effect of gains in tree thinking and on acceptance of evolution at the end of the course.

Data from the S11 through F12 MATE and TTCI instruments were pooled across the four semesters for linear regression analysis. Spearman's rho $(\rho)$ was calculated using nonparametric correlation (Sokal and Rohlf 2012; Theobald and Freeman 2014) to evaluate the individual relationships among students' background data, their tree thinking ability, and their acceptance of evolution. Multiple linear regression analysis of $M_{A T E} E_{P R E}$ scores used background data (e.g., year, previous biology, etc.), whether students had previously seen or learned to read phylogenetic trees, and the $\mathrm{TTCI}_{\mathrm{PRE}}$ score as predictors. Multiple linear regression analysis of MATE $\mathrm{POST}_{\mathrm{P}}$ scores included background data, MATE $\mathrm{PRE}_{\mathrm{PR}}, \mathrm{TTCI}_{\mathrm{PRE}}$, and $\mathrm{TTCI}_{\mathrm{POST}}$ scores in the model. Analysis of MATEPOST scores was also conducted with TTCI scores replaced by $c_{T}$ values to measure correlations between acceptance of evolution and change in TTCI pretest and posttest scores.

\section{Results}

A total of 332 students participated in the study across all six semesters (Table 1). Study participants reflected the typical composition of students in BIOL 1134, with most being sophomores (40.5\%) majoring in the life sciences $(95.9 \%)$. Overall, $53.6 \%$ had previously completed at least one semester of introductory biology at the university level. Because participation in the study was voluntary, it is possible that self-selection bias could potentially influence the results. However, we did not notice any differences in student characteristics, assessment instrument scores, or responses to assessment instrument questions between participants and other course enrollees that would suggest participants were dissimilar from course enrollees overall. Furthermore, study participants' UET and TTCI scores showed a range of tree-thinking abilities, and scores on MATE pretests and posttests ranged from very high acceptance to very low acceptance of evolution. Therefore, we are confident that was no bias towards students with high tree-thinking skills or initial acceptance of evolution. Unfortunately, the procedures to collect the necessary data and methods to statistically detect, identify, and correct for the myriad of potential factors that can contribute to self-selection bias (Cuddeback et al. 2004) are beyond the scope of this study.

\section{Tree Thinking and Acceptance of Evolution in F09 and S10 Semesters}

The mean UET score (Table 2) was significantly higher in posttests than pretests for both semesters (F09: $t=3.86$, $\mathrm{df}=14, p<0.01$; S10: $t=3.77, \mathrm{df}=12, p<0.01)$ and showed a normalized change increase of $c_{U}=0.28 \pm 0.31$ (mean $\pm \mathrm{SD}$ ) in F09 and $c_{U}=0.23 \pm(0.2)$ in S10. Analysis of pretest responses to the UET assessment administered in F09 and S10 identified similar initial misconceptions (Table 2). In both pretests, students had a poor understanding of how time is represented in phylogenies and they frequently used node counting and reading across the tips to determine relationships. Consequently, rotations of trees at the nodes were thought to indicate different evolutionary relationships among lineages. Node counting was used to determine relatedness by 73 and $82 \%$ of students in F09 and S10 pre-tests, respectively. 
Table 1 Participant background information

\begin{tabular}{|c|c|c|c|c|c|c|c|}
\hline Semester (N) & F09 (15) & S10 (13) & S11 (101) & F11 (61) & S12 (79) & F12 (63) & Total (332) \\
\hline \multicolumn{8}{|l|}{ Year (\%) } \\
\hline Freshman & 28.6 & 50.0 & 40.6 & 6.6 & 31.6 & 4.3 & 24.6 \\
\hline Sophomore & 57.1 & 36.4 & 33.7 & 42.6 & 48.1 & 34.8 & 40.5 \\
\hline Junior & 9.5 & 13.6 & 16.8 & 32.8 & 12.7 & 39.1 & 22.5 \\
\hline Senior & 4.8 & 0.0 & 8.9 & 18.0 & 7.6 & 21.8 & 12.4 \\
\hline \multicolumn{8}{|c|}{ Life science major (\%) } \\
\hline Life science & 95.2 & 92.4 & 96.0 & 96.7 & 94.9 & 95.7 & 95.9 \\
\hline Not life-science & 4.8 & 7.6 & 4.0 & 3.3 & 5.1 & 4.3 & 4.1 \\
\hline \multicolumn{8}{|c|}{ Previous University/College Level Biology (\%) } \\
\hline Yes & 52.8 & 45.4 & 65.3 & 67.2 & 74.7 & 82.6 & 53.6 \\
\hline No & 47.2 & 55.6 & 34.7 & 32.8 & 25.3 & 17.4 & 46.4 \\
\hline
\end{tabular}

Participant year in school, major, and previous university biology experience for each semester and pooled total responses across all study semesters.

Table 2 Participant tree reading misconceptions, deficient skills, and mean score on the understanding evolutionary trees (UET) assessment

\begin{tabular}{|c|c|c|c|c|}
\hline & F09 & F09 & $\mathrm{S} 10$ & $\mathrm{~S} 10$ \\
\hline & Pretest & Posttest & Pretest & Posttest \\
\hline \multicolumn{5}{|l|}{ Misconception } \\
\hline Representation of time in trees & $60 \%$ & $0 \%$ & $85 \%$ & $0 \%$ \\
\hline Node counting & $73 \%$ & $0 \%$ & $82 \%$ & $15 \%$ \\
\hline Reading across tips & $33 \%$ & $47 \%$ & $31 \%$ & $54 \%$ \\
\hline $\begin{array}{l}\text { How character change shown } \\
\text { in trees }\end{array}$ & $40 \%$ & $0 \%$ & $77 \%$ & $8 \%$ \\
\hline \multicolumn{5}{|l|}{ Deficient skill } \\
\hline Read traits from a tree & $67 \%$ & $20 \%$ & $54 \%$ & $23 \%$ \\
\hline Deduce ancestral traits & $40 \%$ & $7 \%$ & $54 \%$ & $8 \%$ \\
\hline $\begin{array}{l}\text { Identify identical trees with dif- } \\
\text { ferent node rotations }\end{array}$ & $53 \%$ & $27 \%$ & $62 \%$ & $31 \%$ \\
\hline Construct a tree & $66 \%$ & $19 \%$ & $69 \%$ & $8 \%$ \\
\hline Mean UET score (SD) & $2.6(1.5)$ & $4.0(1.3)$ & $1.5(1.2)$ & $3.0(0.9)$ \\
\hline
\end{tabular}

Percentage of students displaying a misconceptions about phylogentic trees or deficiency in skills necessary to read phylogenetic trees in pretest and posttests administered during the $\mathrm{F} 09(\mathrm{~N}=15)$ and $\mathrm{S} 10(\mathrm{~N}=13)$ semesters. A perfect score on the UET is 7.

However, the frequency of node counting decreased by over $70 \%$ in posttests for both semesters. Surprisingly, the use of reading across the tips to determine relatedness increased slightly in posttests for both semesters. Students had difficulty reading how traits of different lineages are represented in trees in pretests. They also considered taxa on branches at the left of the phylogeny to be older or "less evolved" than taxa on branches on the right side of the phylogeny. Although many students had difficulty constructing a phylogenetic tree when given a small data set for five hypothetical taxa in pretests, they showed marked improvement in their ability to construct a simple phylogentic tree in the posttest.

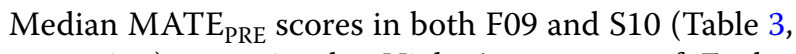
top portion) were in the High Acceptance of Evolution category (MATE scores 77-88). MATE $_{\text {POST }}$ scores increased in both semesters but were significantly greater than $\mathrm{MATE}_{\mathrm{PRE}}$ in the S10 semester only. The interquartile range showed a greater increase in S10 than F09. In

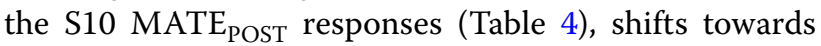
increased acceptance of evolution were particularly clear in questions probing students' attitudes on the occurrence of evolution (M1, M3, M15, M19), the evidence supporting evolutionary theory (M6, M7, M8, M11), the scientific validity of evolutionary theory (M2, M4, M10, M12, M16, M20), the scientific applicability of evolutionary theory (M9, M13, M14, M18,), and the acceptance of evolutionary theory in the scientific community (M5, M17). Normalized change for MATE in S10, the semester in which tree thinking was integrated into the curriculum, was almost twice as large the normalized change for MATE in F09 (Table 3).

\section{Tree Thinking and Acceptance of Evolution in S11 Through F12 Semesters}

Mean $\mathrm{TTCI}_{\mathrm{POST}}$ scores were significantly higher than mean $\mathrm{TTCI}_{\mathrm{PRE}}$ scores for all individual semesters and in the pooled data (Table 5, Additional file 3). Students who reported having previously taken introductory biology or previously seen or learned to read phylogenetic trees had significantly better tree reading than those who had not (Table 6). Within pretests and posttests, there were no differences in TTCI scores among students in different years of school or between majors and non-majors. Normalized change scores, $c_{T}$, showed an average increase of $33 \%$ across all questions in pooled data, with a low of $15 \%$ in S12 and a high of $46 \%$ in S11 (Table 5). Reliability analysis of the TTCI had a Cronbach's $\alpha$ of 0.60 and 0.68 in the pretest and posttest, respectively, indicating that 
Table 3 Measure of the acceptance of the theory of evolution (MATE) scores

\begin{tabular}{|c|c|c|c|c|c|c|c|}
\hline \multirow[t]{2}{*}{ Semester } & \multirow[t]{2}{*}{$\mathrm{N}$} & \multicolumn{2}{|c|}{ MATE $_{\mathrm{PRE}}$} & \multicolumn{2}{|c|}{ MATE } & \multirow[t]{2}{*}{$c_{M}$} & \multirow[t]{2}{*}{ (SD) } \\
\hline & & Mdn & {$[\min , I Q R, \max ]$} & Mdn & {$[\min , I Q R, \max ]$} & & \\
\hline F09 & 15 & $77^{\mathrm{A}}$ & {$[43,69-85,100]$} & $79^{A B}$ & {$[60,69-91,100]$} & 0.15 & $(0.48$ \\
\hline S10 & 13 & $78^{\mathrm{A}}$ & {$[53,60-86,100]$} & $83^{\mathrm{B}}$ & {$[60,76-95,100]$} & 0.28 & $(0.35)$ \\
\hline S11 & 101 & $76^{\mathrm{A}}$ & {$[24,66-83,100]$} & $78^{B}$ & {$[47,68-90,100]$} & 0.20 & $(0.30$ \\
\hline F11 & 61 & $82^{\mathrm{A}}$ & {$[31,67-96,100]$} & $86^{\mathrm{B}}$ & {$[42,76-98,100]$} & 0.25 & $(0.36)$ \\
\hline S12 & 79 & $81^{\mathrm{A}}$ & {$[35,70-94,100]$} & $88^{B}$ & {$[39,75-97,100]$} & 0.30 & $(0.35)$ \\
\hline $\mathrm{F} 12$ & 63 & $78^{\mathrm{A}}$ & {$[35,68-93,100]$} & $84^{B}$ & {$[39,75-98,100]$} & 0.19 & $(1.00)$ \\
\hline Total & 304 & $78^{\mathrm{A}}$ & {$[24,68-92,100]$} & $83^{B}$ & {$[39,74-96,100]$} & 0.24 & $(0.53)$ \\
\hline
\end{tabular}

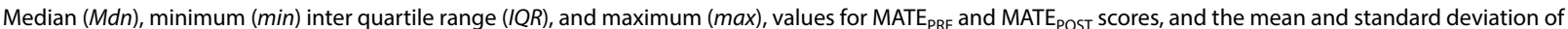
normalized change $\left(c_{M}, S D\right)$ for individual semesters and for total data pooled across S11, F11, S12, and F12. Within semesters and for the total data pooled across S11, $\mathrm{F} 11, \mathrm{~S} 12$, and F12, median MATE $\mathrm{PRE}_{\text {and MATE }}$ asT values followed by different letters are significantly different $(p<0.05)$ in Wilcoxon Ranked Sum tests. N = sample size. MATE scores can range from 20 to 100.

the assessment instrument questions are measuring the same conceptual construct.

Pretest TTCI assessment showed that in approximately half of the responses, students correctly answered that phylogenies show relationships among lineages indicated by lines in the diagram (Fig. 1, Table 7). Slightly over one-third of responses correctly identified how time is represented in a phylogeny. Only one fourth correctly responded that nodes indicate where lineages diverge, but approximately one third held the misconception that nodes indicated where lineages came together or hybridized. Students correctly described relationships shown in phylogenies in half of their $\mathrm{TTCI}_{\mathrm{PRE}}$ responses. As in F09 and S10, node counting was used to determine relationships in phylogenies to a greater extent than reading across the tips. Students could generally identify identical trees showed the same branching pattern of relationships despite node rotations. However, there was a low percentage of correct answers in questions asking students to interpret how trait evolution and speciation is shown in trees. Posttest responses showed improvement in all areas (Fig. 1; Table 7). In posttests, a greater percentage of responses correctly described the components of a phylogenetic tree, and students improved in their ability to determine relationships and interpret traits in trees. Although the frequency of node counting to determine relationships decreased in the TTCI posttest, it still tended to used with greater frequency than reading across the tips. Responses in the TTCI posttest showed increases in correct responses of $15 \%$ or less in Questions T1, T5, T6, T7, and T11. Other questions showed larger increases of $20-40 \%$ in the percentage of correct answers.

Looking across questions, TTCI pretest discrimination index values had an average of $D=0.45 \pm 0.130$ (indicating that the percentage of correct answers to pretest questions was $45 \%$ higher in the $U_{27} \%$ group than the $L_{27} \%$ group) (Table 7). Questions such as T4 had low $D$ values due to low percentages of correct answers in the $U_{27 \%}$ and $L_{27 \%}$ groups, while questions such as T5 and T6 had high percentages of correct answers in all groups. Most informative were the questions with the higher $D$-values (i.e., T1, T9, T12, and T13) which showed that the tree thinking skills that seemed to be most difficult for the low scoring students involved determining relationships and interpreting information about speciation and character evolution.

Median MATE $_{\mathrm{PRE}}$ scores were in the High Acceptance of Evolution category (MATE scores 77-88), in combined data and for F11, S12, and F12 (Table 3, lower portion) and in the Moderate Acceptance of Evolution category (MATE scores 65-76) for S11. Median MATE $_{\text {POST }}$ scores were in the High Acceptance category overall and for individual semesters. The median MATEPOST $(M d n=82.50)$ was significantly higher $(Z=7.97$, $p<0.001)$ than MATE $_{\mathrm{PRE}}(M d n=79.00)$ in pooled data and within semesters (S11: $Z=2.60, p=0.009$; F11: $Z=3.23, p=0.001$; S12: $Z=4.47, p<0.001$; F12: $Z=4.90, p<0.001)$. Reliability analysis of the MATE showed excellent internal consistency, with Cronbach's $\alpha$ values of 0.95 in pretests and 0.925 in posttests.

The only significant differences in MATE pretest or posttest scores detected among different student categories were for year in school in which seniors had significantly higher MATE $_{\mathrm{PRE}}$ and MATE $\mathrm{POST}$ scores than students in other years of school (Table 6). Median MATE posttest scores were significantly higher than pretest scores in all categories except for students who were not life science majors and students who had not previously completed introductory biology. Mean normalized change across semesters for MATE scores were significantly greater than zero 
Table 4 Responses to MATE pretest and posttest responses F09 and S10

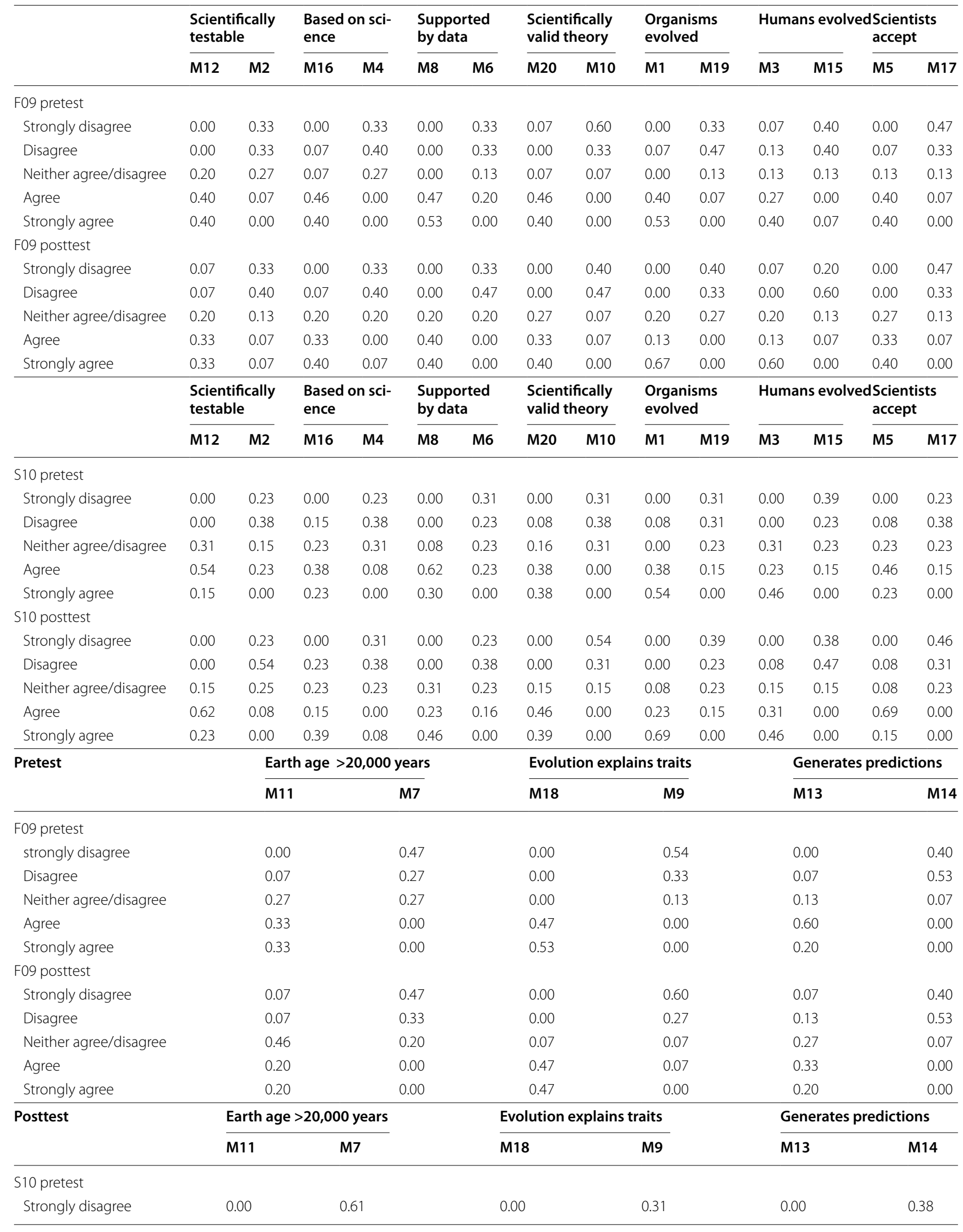


Table 4 continued

\begin{tabular}{|c|c|c|c|c|c|c|}
\hline \multirow[t]{2}{*}{ Posttest } & \multicolumn{2}{|c|}{ Earth age $>20,000$ years } & \multicolumn{2}{|c|}{ Evolution explains traits } & \multicolumn{2}{|c|}{ Generates predictions } \\
\hline & M11 & M7 & M18 & M9 & M13 & M14 \\
\hline Disagree & 0.00 & 0.23 & 0.00 & 0.23 & 0.08 & 0.23 \\
\hline Neither agree/disagree & 0.15 & 0.08 & 0.23 & 0.31 & 0.00 & 0.31 \\
\hline Agree & 0.46 & 0.08 & 0.54 & 0.15 & 0.84 & 0.08 \\
\hline Strongly agree & 0.39 & 0.00 & 0.23 & 0.00 & 0.08 & 0.00 \\
\hline \multicolumn{7}{|l|}{ S10 posttest } \\
\hline Strongly disagree & 0.00 & 0.62 & 0.00 & 0.23 & 0.00 & 0.46 \\
\hline Disagree & 0.08 & 0.15 & 0.00 & 0.69 & 0.00 & 0.15 \\
\hline Neither agree/disagree & 0.08 & 0.23 & 0.15 & 0.08 & 0.15 & 0.31 \\
\hline Agree & 0.38 & 0.00 & 0.62 & 0.00 & 0.62 & 0.08 \\
\hline Strongly agree & 0.46 & 0.00 & 0.23 & 0.00 & 0.23 & 0.00 \\
\hline
\end{tabular}

Percentage of Likert scale response for 20 statements about evolution (designated M1-M20) from the MATE pretest and posttest in the non-tree-thinking (F09) and tree-thinking (S10) semesters. Pairs of positively and negatively worded statements are organized under statement topics. Columns with negatively worded statement responses are shaded.

a Statements: M1. Organisms existing today are the result of evolutionary processes that have occurred over millions of years. M2. The theory of evolution is incapable of being scientifically tested. M3. Modem humans are the product of evolutionary processes that have occurred over millions of years. M4. The theory of evolution is based on speculation and not valid scientific observation and testing. M5. Most scientists accept evolutionary theory to be a scientifically valid theory. M6. The available data are ambiguous as to whether evolution actually occurs. M7. The age of the earth is less than 20,000 years. M8. There is a significant body of data which supports evolutionary theory. M9. Organisms exist today in essentially the same form in which they always have. M10. Evolution is not a scientifically valid theory. M11. The age of the earth is at least 4 billion years. M12. Current evolutionary theory is the result of sound scientific research and methodology. M13. Evolutionary theory generates testable predictions with respect to the characteristics of life. M14. The theory of evolution cannot be correct since it disagrees with the account of creation in different religious texts. M15. Humans exist today in essentially the same form in which they always have. M16. Evolutionary theory is supported by factual, historical, and laboratory data. M17. Much of the scientific community doubts if evolution occurs. M18. The theory of evolution brings meaning to the diverse characteristics and behaviors observed in living forms. M19. With few exceptions, organisms on earth came into existence at about the same time. M20. Evolution is a scientifically valid theory.

Table 5 Tree-Thinking Concept Inventory scores

\begin{tabular}{llllllll}
\hline Semester & $\mathbf{N}$ & TTCl $_{\text {PRE }}$ & (SD) & TTCl $_{\text {POST }}$ & (SD) & $\boldsymbol{c}_{\mathbf{T}}$ & (SD) \\
\hline S11 & 101 & $6.38^{\mathrm{A}}$ & $(1.85)$ & $9.88^{\mathrm{B}}$ & $(2.58)$ & 0.46 & $(0.32)$ \\
$\mathrm{F} 11$ & 61 & $6.31^{\mathrm{A}}$ & $(2.29)$ & $9.62^{\mathrm{B}}$ & $(2.41)$ & 0.38 & $(0.37)$ \\
S12 & 79 & $8.28^{\mathrm{A}}$ & $(3.05)$ & $9.06^{\mathrm{B}}$ & $(2.61)$ & 0.15 & $(0.32)$ \\
F12 & 63 & $6.77^{\mathrm{A}}$ & $(2.96)$ & $9.33^{\mathrm{B}}$ & $(2.86)$ & 0.28 & $(0.48)$ \\
Total & 304 & $6.94^{\mathrm{A}}$ & $(2.64)$ & $9.50^{\mathrm{B}}$ & $(2.62)$ & 0.33 & $(0.39)$ \\
\hline
\end{tabular}

Mean and standard deviation (SD) for TTCl $\mathrm{PRE}_{\text {, }} \mathrm{TTCl}_{\mathrm{POST}}$ and $c_{T}$ for individual $\mathrm{S} 11, \mathrm{~F} 11, \mathrm{~S} 12$, and $\mathrm{F} 12$ semesters and total data pooled across semesters. Within semesters,

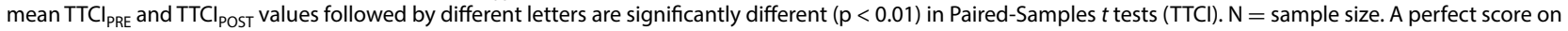
the TTCl is 14 .

$(t=7.648, \mathrm{df}=295, p<0.001)$ and showed an average increase of $23 \%\left(c_{M}=0.23 \pm 0.53 \mathrm{~N}=296\right)$. A large majority of the pretest and posttest responses from students in the $U_{27} \%$ group were in Likert categories indicating high acceptance of evolution, whereas pretest and posttest responses in the $L_{27} \%$ group spanned a greater range of Likert categories (Table 8). Despite covering the scientific evidence of evolution during the semester, posttest responses showed that low acceptance of evolution persisted in some students. However, there were shifts in the MATE posttest responses of the $L_{27} \%$ group in statements that address the basis of evolutionary theory on data and scientific research (Table 8).

\section{Correlation and Linear Regression Analyses of TTCI and MATE}

Pooling across the S11 through S12 semesters, MATE ${ }_{\text {PRE }}$ scores had a significant, positive correlation with all variables except year in school and major (Table 9). The correlation coefficient calculated in regression analysis of $\operatorname{MATE}_{\mathrm{PRE}}$ was low $\left(R=0.309, F_{(6,297)}=5.21, p<0.001\right)$, and the only significant predictors of $\mathrm{MATE}_{\mathrm{PRE}}$ in the model were the $\mathrm{TTCI}_{\mathrm{PRE}}$ score and whether a student had previously seen phylogenetic trees. The $R$ value for MATE $_{\text {POST }}$ over twice as large as in MATE PRE $_{\text {lin- }}$ ear regression analyses $\left(R=0.823, F_{(8,295)}=77.58\right.$, $p<0.001)$. MATE $\mathrm{POST}_{\mathrm{S}}$ scores had a significant, positive correlation with all variables except major and previous 
Table 6 MATE and TTCI response for different student background categories

\begin{tabular}{|c|c|c|c|c|c|c|c|c|c|}
\hline Category & $\mathbf{N}$ & $\mathrm{TTCl}_{\mathrm{PRE}}$ & (SD) & $\mathrm{TTCl}_{\text {POST }}$ & (SD) & $\begin{array}{l}\text { TTCI } \\
\text { Pre-post }\end{array}$ & MATE $_{\mathrm{PRE}}$ & MATE $_{\text {POST }}$ & $\begin{array}{l}\text { MATE } \\
\text { Pre-post }\end{array}$ \\
\hline \multicolumn{10}{|l|}{ Year } \\
\hline Freshman & 73 & $6.86^{\mathrm{A}}$ & $(2.56)$ & $9.23^{A}$ & $(2.58)$ & $* *$ & $76.0^{A}$ & $80.0^{\mathrm{A}}$ & * \\
\hline Sophomore & 119 & $7.05^{\mathrm{A}}$ & $(2.82)$ & $9.47^{\mathrm{A}}$ & $(2.36)$ & $* *$ & $79.0^{\mathrm{A}}$ & $82.0^{\mathrm{A}}$ & * \\
\hline Junior & 72 & $6.94^{\mathrm{A}}$ & $(2.56)$ & $9.71^{A}$ & $(2.85)$ & $* *$ & $78.0^{\mathrm{A}}$ & $83.0^{\mathrm{A}}$ & * \\
\hline Senior & 40 & $6.75^{\mathrm{A}}$ & $(2.53)$ & $9.73^{A}$ & (3.03) & $* *$ & $86.0^{B}$ & $95.0^{\mathrm{B}}$ & $* *$ \\
\hline \multicolumn{10}{|c|}{ Life science major } \\
\hline No & 25 & $7.16^{\mathrm{A}}$ & $(3.01)$ & $9.44^{\mathrm{A}}$ & (3.03) & * & $80.0^{\mathrm{A}}$ & $82.0^{\mathrm{A}}$ & n.s. \\
\hline Yes & 279 & $6.92^{\mathrm{A}}$ & $(2.62)$ & $9.51^{\mathrm{A}}$ & $(2.59)$ & * & $79.0^{\mathrm{A}}$ & $83.0^{\mathrm{A}}$ & $*$ \\
\hline \multicolumn{10}{|c|}{ Previous introductory biology } \\
\hline No & 98 & $6.15^{\mathrm{A}}$ & $(2.60)$ & $8.95^{\mathrm{A}}$ & $(2.68)$ & ** & $72.5^{\mathrm{A}}$ & $73.5^{\mathrm{A}}$ & n.s. \\
\hline Yes & 206 & $7.32^{\mathrm{B}}$ & $(2.60)$ & $9.77^{\mathrm{A}}$ & $(2.56)$ & $* *$ & $76.0^{\mathrm{A}}$ & $81.5^{\mathrm{A}}$ & ** \\
\hline \multicolumn{10}{|c|}{ Have you seen diagrams like these previously? } \\
\hline No & 70 & $6.19^{\mathrm{A}}$ & $(2.62)$ & $8.47^{A B}$ & $(2.89)$ & $* *$ & $72.0^{\mathrm{A}}$ & $75.5^{\mathrm{A}}$ & * \\
\hline Maybe & 62 & $6.19^{\mathrm{A}}$ & $(2.18)$ & $9.52^{A, B}$ & $(2.53)$ & $* *$ & $79.0^{\mathrm{A}}$ & $82.5^{\mathrm{A}}$ & * \\
\hline Yes & 172 & $7.52^{\mathrm{B}}$ & $(2.69)$ & $9.92^{\mathrm{B}, \mathrm{ff}}$ & $(2.39)$ & ** & $82.0^{\mathrm{A}}$ & $85.0^{\mathrm{A}}$ & * \\
\hline \multicolumn{10}{|c|}{ Have you learned to read diagrams like these previously? } \\
\hline No & 144 & $6.33^{\mathrm{A}}$ & $(2.33)$ & $9.10^{\mathrm{A}<\mathrm{B}}$ & (2.83) & $* *$ & $76.5^{\mathrm{A}}$ & $81.0^{\mathrm{A}}$ & $* *$ \\
\hline Yes & 160 & $7.49^{\mathrm{B}}$ & $(2.80)$ & $9.90^{\mathrm{AAB}}$ & $(2.36)$ & $* *$ & $81.0^{\mathrm{A}}$ & $84.5^{\mathrm{A}}$ & ** \\
\hline
\end{tabular}

Mean scores (SD) for TTCl PRE $_{\text {and TTCl }}$ POST, and median scores for MATE PRE, $_{\text {and MATE }}$, for total data pooled across the S11 through F12 semesters for year in school, major, previous introductory biology experience, and whether seen or learned to read phylogenetic trees previously. TTCI PRE, $_{\text {TTCl }}$ OST, MATE $E_{\text {PRE }}$. and MATE POST Values for a given instrument followed by different letters are significantly different $(p<0.05) . \mathrm{N}=$ Sample size. Significance of difference between pretest and posttest scores for a given student category indicated by the following: n.s. $=$ no significant difference, ${ }^{*} p<0.01,{ }^{* *} p<0.001$.

introductory biology experience, but only year in school, $\mathrm{MATE}_{\mathrm{PRE}}$, and TTCI $\mathrm{POST}_{\mathrm{P}}$ were significant predictors of a students' acceptance of evolution as measured by MATE$\mathrm{POST}_{\mathrm{T}}$ at the end of the semester in linear regression model (Table 9). MATE $\mathrm{POST}_{\mathrm{P}}$ also had a high correlation coefficient when TTCI scores were replaced with $c_{T}$ in the model $\left(R=0.822 F_{(7,296)}=87.87, p<0.001\right)$, indicating that final acceptance of evolution in the MATE posttest was not only significantly correlated with a student's initial acceptance of evolution, but also their gains in tree reading ability. The relationship between is improvement in tree thinking and acceptance of evolution is further supported by a significant, positive correlation between $c_{T}$ and $\mathrm{c}_{\mathrm{M}}$ with $\rho=0.127(p<0.05)$.

\section{Discussion}

The present study identified a significant relationship between students' tree thinking and their acceptance of evolution. We found that after completing a semester of introductory biology in which a number of tree-thinking activities emphasizing macroevolution and phylogenetic perspectives were used as an organizing theme throughout the semester, students improved in their ability to read and interpret phylogenetic trees as indicated by significantly higher $\mathrm{TTCI}_{\mathrm{POST}}$ than $\mathrm{TTCI}_{\mathrm{PRE}}$ scores, and showed significantly greater acceptance of evolution as indicated by MATE posttest scores. Many misconceptions about phylogenetic trees, as well as misconceptions and conflicting opinions about evolution were corrected for most students. The assessment instrument responses indicated that the tree-thinking curricular structure, therefore, not only promoted development of the fundamental skills for tree thinking, it also improved acceptance and understanding of the scientific evidence supporting evolution.

In terms of learning tree thinking as a skill, we found that university students at the introductory biology level are capable of learning and applying complex phylogenetic concepts and techniques. Errors detected in pretests, such as not knowing that a phylogeny shows relationships among taxa or that there is a time axis inherent in a phylogeny, indicate that some students have a fundamental misunderstanding of phylogenetic trees and the information they contain. Other errors, such as reading across the tips and node counting, indicate how students who have not been instructed how to correctly read trees use superficial features to interpret phylogenies (Halverson 2011). After completing the different activities and modules, however, students' ability to read and interpret phylogenetic trees was significantly improved (Tables 2, 5). Common misconceptions detected in UET and TTCI pretests (Tables 2, 7; Fig. 1) were not different 
Phylogenies show relationships among lineages (T2)

Correct understanding of time in phylogenies (T1)

Lines in phylogenies indicate different lineages (T3) Nodes in phylogenies indicate speciation/common ancestors (T4)

Nodes in phylogenies indicate hybridization* (T4)

Correctly determine relationships in phylogenies (T6-T9)

Determine relationships by node counting* (T7-T8)

Determine relationships by reading across tips* (T7 -T8)

Correctly identify identical phylogenies with different node rotations (T5 \& T10)

Correctly intrpret traits/speciation in phylogenies

(T11-14)

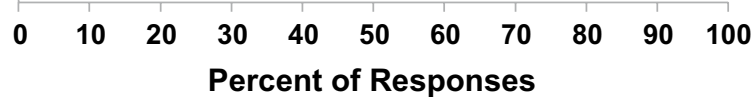

Fig. 1 Summary of concepts and skills from S11-F12 TTCI. Percentage of TTCI responses for different tree-thinking concepts and skills. Misconceptions and incorrect methods of determining relationships are indicated by an asterisk. TTCl questions addressing a concept or skill are given in parenthesis. See Additional file 2 and Table 7.

from those that have been identified in other studies, particularly the high occurrence of node counting. (Baum et al. 2005; Meir et al. 2007; Meisel 2010). Detailed item analysis of TTCI responses demonstrated that many of the mistakes students made when interpreting trees in TTCI pretest questions related to misunderstandings of nodes in phylogenetic trees and the evolutionary events they signify (Fig. 1, Additional file 3). For example, approximately one-fourth of students in the TTCI pretest correctly responded that nodes indicate isolation of lineages, while the majority responded that they indicate other events. Interestingly, $30 \%$ thought that nodes indicated hybridization, which suggests these students may be confusing phylogenies with pedigrees. Although pedigrees and phylogenies are superficially similar, their interpretation is drastically different, particularly at the nodes. Applying principles for pedigree interpretation to a phylogeny could account for students' use of methods such as node counting, which is informative to calculate degree of relatedness in a pedigree but not in a phylogeny.

Our results also showed that after completing a semester of introductory biology that used a tree-thinking curriculum, students demonstrated significantly higher acceptance of evolution (Table 3). At the start of the semester, tree-thinking ability, as indicated by the $\mathrm{TTCI}_{\mathrm{PRE}}$ score, was a predictor of the MATE $\mathrm{PRE}_{\text {score }}$ (Table 9). However, by the end of the course in S11 through F12, students not only had significantly higher TTCI and MATE scores, but there were no longer differences in TTCI and MATE scores between students with different prior experience. In posttest assessment of

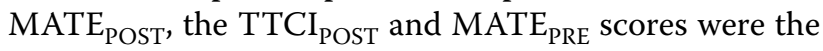
only significant predictors of the MATE $\mathrm{POST}_{\mathrm{PO}}$ score. While the results do not allow a direct conclusion of causality, they strongly indicate that a tree-thinking curriculum that engages students in collecting data, testing hypotheses, interpreting results, and learning phylogenetic techniques can increase students' acceptance of evolution.

Although we have detected a significant relationship between tree thinking and acceptance of evolution, the results of the study also demonstrate that ability to read phylogenetic trees does not in itself translate into significantly greater acceptance of evolution. Although students in the F09 semester had significant improvements in tree thinking, they did not show the corresponding increases in acceptance of evolution. Tree thinking does require understanding fundamental concepts and principles of evolutionary theory. However, promoting increased 
Table 7 Percentage of student responses for each option in $14 \mathrm{TTCl}$ questions ${ }^{\mathrm{a}}$ (labeled T1-T14) in total data pooled across semsters $(N=304)$ and the percentage of correct responses for each question in the $U_{27}$ and $L_{27}$ groups $(N=82)$

\begin{tabular}{|c|c|c|c|c|c|c|c|c|c|c|c|c|c|c|c|}
\hline & $\mathrm{T} 1$ & $\mathrm{~T} 2$ & T3 & $\mathrm{T4}$ & T5 & T6 & T7 & T8 & T9 & T10 & T11 & T12 & T13 & T14 & Mean (SD) \\
\hline \multicolumn{16}{|c|}{ Pre-test } \\
\hline$a$ & 4.1 & 1.3 & 7.8 & 29.7 & 5.7 & 63.8 & 74.0 & 1.4 & 11.7 & 13.5 & 1.4 & 36.8 & 9.8 & 2.4 & \\
\hline$b$ & 24.8 & 53.6 & 47.3 & 7.3 & 78.3 & 7.6 & 13.7 & 45.2 & 6.8 & 14.5 & 14.1 & 25.4 & 15.9 & 19.9 & \\
\hline c & 10.5 & 30.9 & 31.5 & 26.6 & 3.0 & 4.5 & 5.0 & 32.8 & 4.9 & 13.7 & 7.2 & 13.7 & 23.5 & 41.5 & \\
\hline$d$ & 35.5 & 7.3 & 6.8 & 19.5 & 8.3 & 13.1 & 4.8 & 17.9 & 28.8 & 6.0 & 62.8 & 12.3 & 23.9 & 17.5 & \\
\hline$e$ & 25.1 & 6.8 & 6.5 & 16.9 & 4.8 & 11.0 & 2.5 & 2.8 & 47.7 & 52.3 & 14.5 & 11.7 & 26.9 & 18.7 & \\
\hline$U_{27 \%}$ & 59.8 & 72.0 & 64.6 & 34.2 & 91.5 & 76.8 & 95.1 & 51.2 & 81.7 & 73.2 & 75.6 & 69.5 & 54.9 & 42.7 & $67.3(17.5)$ \\
\hline$L_{27 \%}$ & 17.1 & 30.5 & 37.8 & 11.0 & 56.1 & 47.6 & 51.2 & 18.3 & 8.5 & 29.3 & 41.5 & 11.0 & 9.8 & 6.1 & $26.8(17.5)$ \\
\hline$D$ & 0.43 & 0.41 & 0.27 & 0.23 & 0.35 & 0.29 & 0.44 & 0.33 & 0.73 & 0.44 & 0.34 & 0.59 & 0.45 & 0.37 & $0.45(0.13)$ \\
\hline \multicolumn{16}{|c|}{ Post-test } \\
\hline$a$ & 3.9 & 2.9 & 1.4 & 7.3 & 6.3 & 69.0 & 81.9 & 0.3 & 7.5 & 11.8 & 2.2 & 65.1 & 13.3 & 2.5 & \\
\hline$b$ & 13.1 & 74.0 & 88.0 & 17.2 & 88.8 & 3.5 & 2.2 & 37.9 & 1.7 & 4.8 & 29.6 & 17.8 & 11.1 & 25.3 & \\
\hline c & 3.9 & 10.9 & 8.7 & 63.8 & 0.7 & 0.0 & 8.6 & 58.2 & 3.1 & 1.9 & 2.2 & 2.3 & 18.0 & 26.3 & \\
\hline$d$ & 50.3 & 6.3 & 0.7 & 3.6 & 0.7 & 8.2 & 3.5 & 1.6 & 17.0 & 0.6 & 63.8 & 7.4 & 7.3 & 2.5 & \\
\hline$e$ & 28.8 & 5.9 & 1.2 & 8.1 & 3.5 & 19.3 & 3.8 & 1.9 & 70.7 & 80.9 & 2.2 & 7.4 & 50.3 & 43.4 & \\
\hline$U_{27 \%}$ & 65.9 & 90.2 & 98.8 & 89.0 & 95.1 & 81.7 & 96.3 & 89.0 & 97.6 & 97.6 & 80.5 & 89.0 & 91.5 & 74.4 & 88.3 (9.64) \\
\hline$L_{27 \%}$ & 30.5 & 54.9 & 76.8 & 39.0 & 80.5 & 46.3 & 64.6 & 26.8 & 40.2 & 51.2 & 52.4 & 25.6 & 15.9 & 13.4 & $44.2(20.9)$ \\
\hline$D$ & 0.35 & 0.35 & 0.22 & 0.50 & 0.15 & 0.35 & 0.32 & 0.62 & 0.57 & 0.46 & 0.28 & 0.63 & 0.76 & 0.61 & $0.44(0.18)$ \\
\hline
\end{tabular}

Discrimination Index $(D)$ values are given for each TTCl question in the pretest and post-test. Italic indicates percentage of correct answers.

a Question topic areas. Questions 1-4: representation of time and parts of a phylogeny. Questions 5 and 10: comparing node rotations and branching patterns among phylogenies. Questions 6-9, 13: determining relationships among taxa. Question 11: evaluating trait evolution. Questions 12 and 14: comprehensive interpretation of information in phylogeny. Complete TTCl assessment with questions is available in Additional file 1.

acceptance of evolution requires that students also put tree thinking into a larger context and understand how phylogenies serve as a conceptual starting point for researchers investigating evolution. We think that this is the key benefit of our tree-thinking curriculum. It promotes increased acceptance of evolution by helping students improve their understanding of the nature of science and how evolution is studied scientifically (Johnson and Peeples 1987; Southerland et al. 2001). For example, MATE pretest responses in all semesters of the study (Tables 4,8 ) indicated that although students understood evolution to be a scientific theory, many did not understand how evolution research is conducted or how the available scientific data are evidence of evolutionary processes. Students in the $L_{27 \%}$ groups of the MATE $\mathrm{PRE}_{\mathrm{P}}$ assessment in particular responded that although scientists accept evolution, they thought that evolutionary theory is neither based on valid scientific experimentation and data nor is it a valid scientific theory (Table 8). These conflicting views strongly suggest that basic unfamiliarity with the nature of science in evolutionary biology research is likely an important factor shaping students' acceptance of evolutionary theory.

Doubts about the existence and validity of evidence supporting evolution not uncommon (Alters 2005; Miller et al. 2006; Moore 2008; Smith 2010; Yates and Marek
2014), particularly given the complexities of some data (e.g., molecular sequences) and unfamiliar methods of analysis (e.g., cladistics). Significant increases in acceptance of evolution for S10 students overall and in the $L_{27} \%$ group were primarily due to responses reporting greater acceptance of the data and research supporting evolutionary theory (e.g., statements M2, M4, M6, M8, M12, and M16) in the MATE posttest after the tree-thinking semester, whereas the responses to these questions in the F09 non-tree-thinking semester remained largely the same (Tables 3, 4). Similar changes were also detected in MATE $_{\text {POST }}$ responses for the other four semesters of this study (Tables 3,8 ). These results indicate that an increased emphasis on macroevolutionary research and repeated exposure to and experience working with different forms of phylogenetic data not only improved students' understanding of these topics, but also clarified how evolution research is conducted, and thereby resulted in a significant increase in students' acceptance of evolution under the tree-thinking curriculum.

Increased proficiency in a technique or method of analysis such as phylogenetic analysis does not automatically relate to increased acceptance of evolutionary theory (Sinatra et al. 2008). Instead, we would suggest that the tree-thinking curriculum fosters a deeper understanding of how evolution is scientifically studied and validated, 
Table 8 Pooled MATE statement responses S11-F12

\begin{tabular}{|c|c|c|c|c|c|c|c|c|c|c|c|c|c|c|}
\hline \multirow[t]{2}{*}{ Pretest } & \multicolumn{2}{|c|}{$\begin{array}{l}\text { Scientifically } \\
\text { testable }\end{array}$} & \multicolumn{2}{|c|}{$\begin{array}{l}\text { Based on sci- } \\
\text { ence }\end{array}$} & \multicolumn{2}{|c|}{$\begin{array}{l}\text { Supported } \\
\text { by data }\end{array}$} & \multicolumn{2}{|c|}{$\begin{array}{l}\text { Scientifically } \\
\text { valid theory }\end{array}$} & \multicolumn{2}{|c|}{$\begin{array}{l}\text { Organisms } \\
\text { evolved }\end{array}$} & \multicolumn{2}{|c|}{$\begin{array}{l}\text { Humans } \\
\text { evolved }\end{array}$} & \multicolumn{2}{|c|}{$\begin{array}{l}\text { Scientists } \\
\text { accept }\end{array}$} \\
\hline & M12 & M2 & M16 & M4 & M8 & M6 & M20 & M10 & M1 & M19 & M3 & M15 & M5 & M17 \\
\hline \multicolumn{15}{|l|}{ Total } \\
\hline Strongly disagree & 2.3 & 31.2 & 2.9 & 33.1 & 3.2 & 27.2 & 3.5 & 37.8 & 6.4 & 28.3 & 10.4 & 32.1 & 0.6 & 31.6 \\
\hline Disagree & 7.4 & 38.6 & 8.0 & 42.1 & 6.4 & 41.2 & 7.1 & 36.8 & 3.8 & 34.0 & 8.1 & 31.7 & 4.2 & 42.8 \\
\hline Neither agree/disagree & 16.8 & 20.6 & 16.7 & 11.9 & 14.0 & 18.2 & 16.3 & 14.6 & 9.6 & 20.6 & 14.3 & 18.1 & 15.4 & 16.6 \\
\hline Agree & 44.2 & 6.8 & 46.0 & 9.0 & 39.2 & 10.5 & 39.7 & 7.3 & 33.0 & 12.7 & 29.9 & 13.0 & 47.8 & 6.7 \\
\hline Strongly agree & 29.4 & 2.9 & 26.4 & 3.9 & 37.3 & 2.9 & 33.3 & 3.5 & 47.1 & 4.4 & 37.3 & 5.1 & 32.1 & 2.2 \\
\hline \multicolumn{15}{|l|}{ Upper $27 \%$} \\
\hline Strongly disagree & 0.0 & 80.0 & 0.0 & 83.5 & 0.0 & 72.9 & 0.0 & 89.4 & 0.0 & 75.3 & 0.0 & 80.0 & 0.0 & 76.5 \\
\hline Disagree & 0.0 & 17.6 & 0.0 & 11.8 & 0.0 & 22.4 & 0.0 & 5.9 & 0.0 & 10.6 & 1.2 & 9.4 & 1.2 & 17.6 \\
\hline Neither agree/DISAGREE & 1.2 & 1.2 & 1.2 & 2.4 & 0.0 & 2.4 & 0.0 & 2.4 & 1.2 & 9.4 & 2.4 & 3.5 & 0.0 & 3.5 \\
\hline Agree & 15.3 & 0.0 & 16.5 & 0.0 & 4.7 & 0.0 & 3.5 & 0.0 & 3.5 & 2.4 & 2.4 & 4.7 & 21.2 & 0.0 \\
\hline Strongly AGREE & 83.5 & 1.2 & 82.4 & 2.4 & 95.3 & 2.4 & 96.5 & 2.4 & 95.3 & 2.4 & 94.1 & 2.4 & 77.6 & 2.4 \\
\hline \multicolumn{15}{|l|}{ Lower $27 \%$} \\
\hline Strongly disagree & 8.5 & 6.0 & 10.8 & 5.9 & 11.8 & 5.8 & 11.9 & 3.5 & 21.4 & 4.7 & 34.1 & 5.8 & 1.2 & 11.8 \\
\hline Disagree & 23.2 & 22.9 & 25.3 & 30.6 & 23.5 & 22.1 & 21.4 & 32.6 & 13.1 & 22.1 & 23.2 & 19.8 & 9.4 & 34.1 \\
\hline Neither agree/disagree & 43.9 & 43.4 & 45.8 & 31.8 & 40.0 & 39.5 & 42.9 & 38.4 & 25.0 & 38.4 & 28.0 & 34.9 & 22.4 & 37.6 \\
\hline Agree & 23.2 & 18.1 & 18.1 & 21.2 & 24.7 & 27.9 & 22.6 & 16.3 & 33.3 & 26.7 & 13.4 & 25.6 & 55.3 & 12.9 \\
\hline Strongly agree & 1.2 & 9.6 & 0.0 & 10.6 & 0.0 & 4.7 & 1.2 & 9.3 & 7.1 & 8.1 & 1.2 & 14.0 & 11.8 & 3.5 \\
\hline \multirow[t]{2}{*}{ Posttest } & \multicolumn{2}{|c|}{$\begin{array}{l}\text { Scientifically } \\
\text { testable }\end{array}$} & \multicolumn{2}{|c|}{$\begin{array}{l}\text { Based on } \\
\text { science }\end{array}$} & \multicolumn{2}{|c|}{$\begin{array}{l}\text { Supported } \\
\text { by data }\end{array}$} & \multicolumn{2}{|c|}{$\begin{array}{l}\text { Scientifically } \\
\text { valid theory }\end{array}$} & \multicolumn{2}{|c|}{$\begin{array}{l}\text { Organisms } \\
\text { evolved }\end{array}$} & \multicolumn{2}{|c|}{$\begin{array}{l}\text { Humans } \\
\text { evolved }\end{array}$} & $\begin{array}{l}\text { Scier } \\
\text { acce }\end{array}$ & \\
\hline & M12 & M2 & M16 & M4 & M8 & M6 & M20 & M10 & M1 & M19 & M3 & M15 & M5 & M17 \\
\hline Total & & & & & & & & & & & & & & \\
\hline Strongly disagree & 0.6 & 37.4 & 1.9 & 44.4 & 1.3 & 36.9 & 2.2 & 48.4 & 3.8 & 36.3 & 6.8 & 38.5 & 1.3 & 40.4 \\
\hline Disagree & 5.8 & 37.7 & 4.8 & 37.1 & 3.5 & 39.8 & 4.2 & 36.3 & 3.8 & 32.2 & 5.8 & 37.3 & 2.9 & 40.8 \\
\hline Neither agree/disagree & 13.1 & 13.7 & 12.5 & 9.6 & 11.1 & 13.7 & 10.2 & 8.9 & 7.3 & 18.0 & 15.2 & 10.2 & 8.6 & 13.4 \\
\hline Agree & 42.6 & 7.7 & 46.0 & 6.4 & 39.5 & 8.3 & 41.5 & 5.1 & 32.1 & 10.0 & 29.7 & 8.6 & 44.8 & 4.5 \\
\hline Strongly agree & 37.8 & 3.5 & 34.8 & 2.6 & 44.6 & 1.3 & 41.9 & 1.3 & 53.0 & 3.5 & 42.6 & 5.4 & 42.5 & 1.0 \\
\hline Upper $27 \%$ & & & & & & & & & & & & & & \\
\hline Strongly disagree & 0.0 & 89.4 & 1.2 & 100.0 & 0.0 & 98.8 & 0.0 & 100.0 & 0.0 & 87.1 & 0.0 & 94.1 & 0.0 & 92.9 \\
\hline Disagree & 0.0 & 7.1 & 0.0 & 0.0 & 0.0 & 1.2 & 0.0 & 0.0 & 0.0 & 8.2 & 0.0 & 4.7 & 1.2 & 5.9 \\
\hline Neither agree/disagree & 0.0 & 0.0 & 0.0 & 0.0 & 0.0 & 0.0 & 0.0 & 0.0 & 0.0 & 1.2 & 2.4 & 0.0 & 1.2 & 1.2 \\
\hline Agree & 2.4 & 0.0 & 3.5 & 0.0 & 0.0 & 0.0 & 0.0 & 0.0 & 1.2 & 1.2 & 2.4 & 0.0 & 10.6 & 0.0 \\
\hline Strongly agree & 97.6 & 3.5 & 95.3 & 0.0 & 100.0 & 0.0 & 100.0 & 0.0 & 98.8 & 2.4 & 95.3 & 1.2 & 87.1 & 0.0 \\
\hline Lower $27 \%$ & & & & & & & & & & & & & & \\
\hline Strongly disagree & 2.4 & 3.5 & 4.8 & 8.1 & 3.5 & 2.3 & 8.3 & 4.7 & 11.8 & 1.2 & 20.5 & 7.1 & 3.5 & 11.6 \\
\hline Disagree & 17.9 & 34.9 & 14.3 & 38.4 & 12.9 & 34.9 & 14.3 & 45.9 & 11.8 & 17.9 & 18.1 & 29.4 & 8.1 & 40.7 \\
\hline Neither agree/disagree & 36.9 & 34.9 & 33.3 & 26.7 & 36.5 & 33.7 & 33.3 & 29.4 & 22.4 & 45.2 & 28.9 & 22.4 & 27.9 & 32.6 \\
\hline Agree & 39.3 & 19.8 & 44.0 & 20.9 & 42.4 & 24.4 & 40.5 & 16.5 & 43.5 & 25.0 & 28.9 & 25.9 & 48.8 & 11.6 \\
\hline Strongly agree & 3.6 & 7.0 & 3.6 & 5.8 & 4.7 & 4.7 & 3.6 & 3.5 & 10.6 & 10.7 & 3.6 & 15.3 & 11.6 & 3.5 \\
\hline Pretest & & Eart & h age $>2$ & 0,000 ye & & & Evolut & n expla & ns traits & & & enerate & predic & ons \\
\hline & & M11 & & & 17 & & M18 & & M9 & & & 113 & & M14 \\
\hline Total & & & & & & & & & & & & & & \\
\hline Strongly disagree & & 5.2 & & & 54.0 & & 2.9 & & 35.9 & & & 1.9 & & 36.2 \\
\hline Disagree & & 3.9 & & & 26.7 & & 6.1 & & 41.0 & & & 7.7 & & 31.1 \\
\hline Neither agree/disagree & & 18.7 & & & 11.9 & & 12.5 & & 12.7 & & & 0.8 & & 19.9 \\
\hline Agree & & 39.0 & & & 5.8 & & 45.2 & & 7.3 & & & 5.5 & & 7.7 \\
\hline
\end{tabular}


Table 8 continued

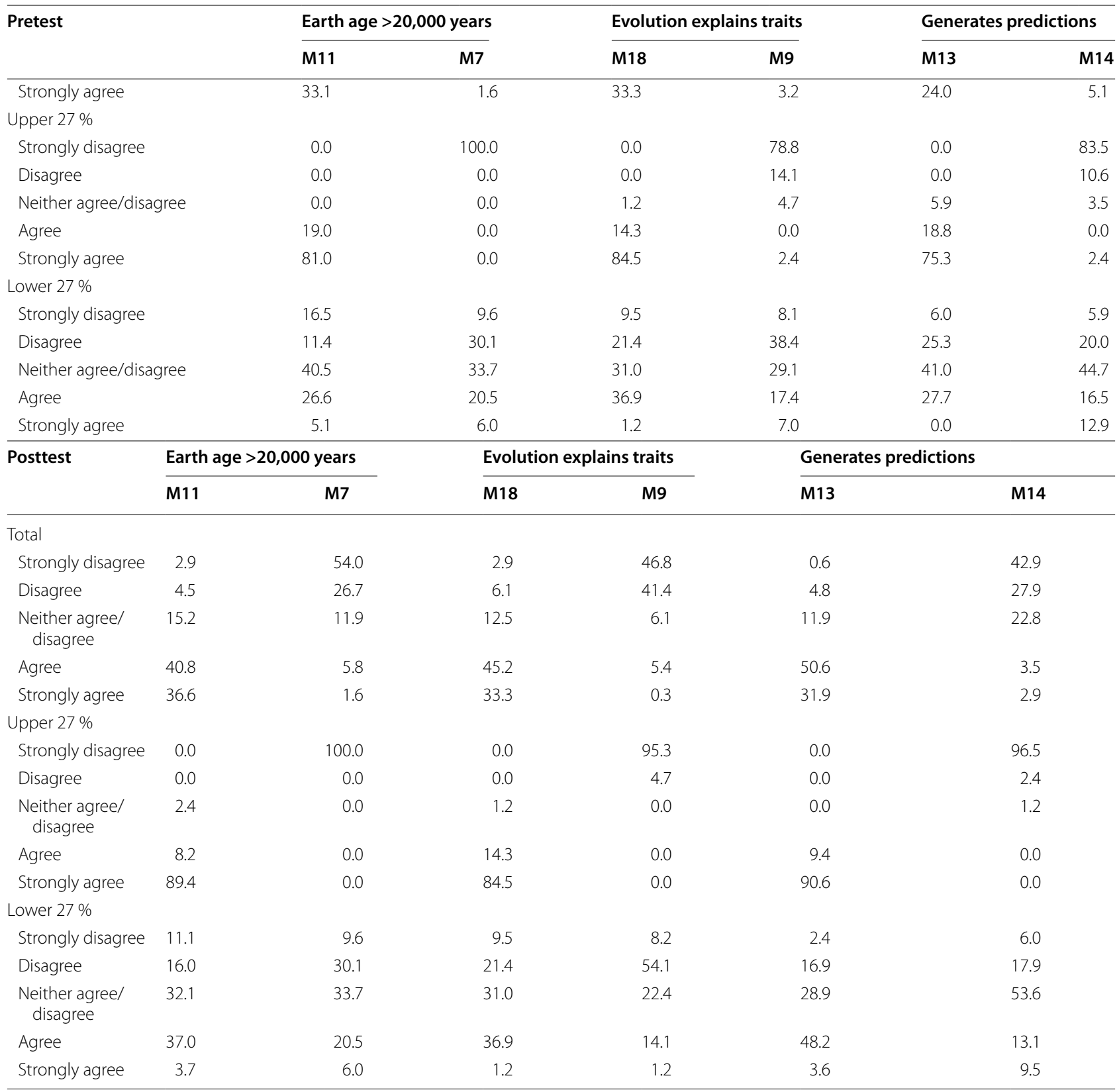

Percentage of Likert scale response for 20 statements about evolution (designated M1-M20) from the MATE pretest and posttest for the S11 through F12 semesters. Pairs of positively and negatively worded statements are organized under statement topics. Negatively worded statement responses are shaded. Percentages are given for the total group of all study participants in S11, F11, S12, and F12 ( N = 304) and for the upper $27 \%$ and lower $27 \%$ of MATE scores. See Table 3 for statements.

which is likely critical to improving acceptance of evolutionary theory. Regardless of what students believe, and MATE responses indicate that some students continue to hold beliefs that are not completely consistent with evolution, students showed an improved understanding of the methods and evidence supporting evolutionary theory, which was responsible for the increased MATE scores. The tree-thinking focus in the introductory curriculum provides a larger, unifying conceptual framework throughout the course that presents, for what is likely the first time for many students, how biologists study evolution.

Evolution is a complex theory that requires synthesis of many different forms of data. By presenting students with tree thinking activities that draw upon examples using ecological, genetic, developmental, behavioral, and other 
Table 9 Correlation and linear regression analysis of TTCI and MATE scores

\begin{tabular}{|c|c|c|c|c|c|}
\hline Variables & $\rho$ & B & Variables & $\rho$ & B \\
\hline MATE $_{\text {PRE }}$ & & & MATE & & \\
\hline Year & 0.109 & 1.268 & Year & $0.189^{* * *}$ & $1.657^{* * *}$ \\
\hline Major & 0.001 & 1.681 & Major & 0.018 & 1.674 \\
\hline College/University Introductory Biology & $0.121^{*}$ & 2.105 & College/University Introductory Biology & 0.096 & -0.031 \\
\hline Seen trees before & $0.236^{* * *}$ & $4.09 * *$ & Seen trees before & $0.255^{*}$ & 1.225 \\
\hline Learned to read previously & $0.135^{*}$ & -0.88 & Learned to read previously & $0.145^{*}$ & 0.297 \\
\hline \multirow[t]{11}{*}{$\mathrm{TTCl}_{\mathrm{PRE}}$} & $0.243^{* * *}$ & $1.297^{* * *}$ & MATE $_{P R E}$ & $0.815^{* * *}$ & $0.637^{* * *}$ \\
\hline & & & $\mathrm{TTCl}_{\mathrm{PRE}}$ & $0.180^{* *}$ & -0.224 \\
\hline & & & $\mathrm{TTCl}_{\text {POST }}$ & $0.354^{* * *}$ & $0.628^{* * *}$ \\
\hline & & & MATE & & \\
\hline & & & Year & $0.189^{* * *}$ & $1.645^{* * *}$ \\
\hline & & & Major & 0.037 & 1.521 \\
\hline & & & College/University Introductory Biology & $0.128^{* *}$ & -0.633 \\
\hline & & & Seen trees before & $0.255^{*}$ & 1.296 \\
\hline & & & Learned to read previously & $0.145^{*}$ & 0.440 \\
\hline & & & MATE $_{P R E}$ & $0.815^{* * *}$ & $0.647^{* * *}$ \\
\hline & & & $c_{T}$ & $0.203^{* * *}$ & $3.431^{* *}$ \\
\hline
\end{tabular}

Model variables, Spearman's rho $(\rho)$ correlation coefficients for each variable, and estimated B-values in linear regression analysis of TTCI and MATE pretest and posttest scores for the S11 through F12 semesters. ${ }^{*} p<0.05,{ }^{* *} p<0.01,{ }^{* * *} p<0.001$.

Response coding. Year: Freshman =1, Sophomore =2, Junior =3, Senior =4, Other = 5. Major: Non-Major =0, Life Science Major $=1$, High School Biology: No =0, yes $=1$. Previous College/University Biology With Evolution: No $=0$, Yes $=1$. Seen phylogenetic trees previously: No $=0$, Not Sure $=1$, Yes $=2$. Learned to read phylogenetic trees previously: $\mathrm{No}=0, \mathrm{Yes}=1$.

forms of data, the tree-thinking curriculum provides a framework to synthesize data across different fields and show how they converge in support of evolutionary theory. Additionally, the curriculum focuses on macroevolution, which is an important, fundamental component of evolutionary theory that often receives scant emphasis in evolution education. The increased emphasis on macroevolution provides additional perspectives on evolution and the nature of science, both of which are necessary to develop a broader understanding, appreciation, and acceptance of evolutionary theory (Johnson and Peeples 1987; Southerland et al. 2001; Southerland and Sinatra 2005; Hawley et al. 2011).

Correctly applying tree thinking requires a fundamental understanding that lineages of different taxa descend and diverge from one another through a series of nested ancestor-descendent relationships. We expected that by establishing how evolution is based on tangible and uncontroversial processes of inheritance, students should develop a better understanding of how genetic data provide a record of successful reproduction and transmission of information across generations. The treethinking curriculum focused on demonstrating how DNA and other forms of data based on genetics (e.g., structural and developmental homology) can provide highly informative, empirical evidence about the historical relationships within and among lineages that can be used in evolutionary studies. By teaching phylogenetic approaches and tree thinking, we predicted that students would learn about and gain experience using the phylogenetic framework biologists use to develop hypotheses and explore questions about how organisms and their features evolve.

Tree thinking involves not only the technical aspect of reading phylogenies, but also using an overarching understanding of evolution as an emergent biological phenomenon and how these diagrams graphically represent the nested hierarchy and descent from a common ancestor that are the core of evolution research. Thus, the ability to read and interpret trees correctly reflects not only proficiency in using specific skills, but also an understanding of the evolutionary basis of these diagrams. The results of our study support the use of tree thinking as a curricular theme in introductory biology education and demonstrate how a curriculum focused on tree thinking helps students learn not only an important skill, but can also promote greater acceptance of evolution. In particular, efforts to improve evolution education should continue to explore the relationship between students' understanding of the nature of science in evolution research and their acceptance of the theory (Johnson and Peeples 1987). Further studies should also strive to identify whether there are certain activities we used or specific aspects of tree-thinking curriculum that have 
a greater influence on correcting misconceptions and increasing acceptance of evolution. By identifying the most useful activities or the attributes of modules that have a particularly effective influence on students' understanding and acceptance of evolution, science education researchers can not only continue to develop activities that improve tree-thinking skills, but also include features in those activities and curricular modifications that are known to promote the greatest increases in understanding and acceptance of evolution.

\section{Additional Files}

Additional file 1: Questions in Understanding Evolutionary Trees Instrument used in F09 and S10.

Additional file 2: Modified version of Nagel's Tree-Thinking Concept Inventory used in S11-F12.

Additional file 3: Total percentage correct responses, percentage correct in $U_{27}$ and $L_{27} \%$, and discrimination index (D) values for 14 Questions (T1-T14) in the TTCl pre-test and post-test in each study semester. See Additional file 1 for TTCI with questions.

\section{Abbreviations}

MATE: measure of the acceptance of the theory of evolution; TTCI: Tree thinking Concept Inventory; UET: understanding evolutionary trees.

\section{Authors' Contributions}

JPG taught and developed the BIOL 1134 course, collected data, and analyzed data. MHH informed students about and recruited students for the study. Both JPG and MHH participated in development and design of the study, and the drafting and editing of the manuscript. All authors read and approved the final manuscript.

\section{Author details}

${ }^{1}$ Department of Biology, University of Oklahoma, Norman, OK 73019, USA. 2 Department of Microbiology and Plant Biology, University of Oklahoma, Norman, OK 73019, USA.

\section{Acknowledgements}

Research funded by NSF DUE \#0940835. Research conducted under OU IRB \#12682. Thanks to M. Jones, J. Cooper, C. Halverson, S. Brownell, and D. Baum who provided valuable comments on different aspects of this research and two anonymous reviewers who provided comments that improved the manuscript.

\section{Compliance with Ethical Guidelines}

\section{Competing Interests}

The authors declare that they have no competing interests.

Received: 30 March 2015 Accepted: 1 August 2015

Published online: 13 August 2015

\section{References}

Alters, B. J. (2005). Teaching biological evolution in higher education Methodological, religious, and nonreligious issues. Sudbury: Jones and Bartlett Publishers.

Alters, B. J., \& Nelson, C. E. (2002). Perspective: teaching evolution in higher education. Evolution, 56, 1891-1901.

Aronova-Tiuntseva, Y., and Herreid, C. F. (2003). Hemophilia: the royal disease. National Center for Case Study Teaching in Science Case Study Collection. http://sciencecases.lib.buffalo.edu/cs/files/hemo.pdf. Accessed 18 April 2005.
Baum, D. A., \& Offner, S. (2008). Phylogenies and tree thinking. American Biology Teacher, 70, 222-229.

Baum, D. A., \& Smith, S. D. (2013). Tree thinking: an introduction to phylogenetic biology. Greenwood Village: Roberts and Company Publishers.

Baum, D. A., Smith, S. D., \& Donovan, S. S. (2005). Evolution the tree thinking challenge. Science, 310, 979-980.

Berkman, M., Pacheco, J., \& Plutzer, E. (2008). Evolution and creationism in America's classrooms: a national portrait. PLOS Biology, 6, e124. doi:10.1371/journal.pbio.0060124.

Berkman, M., \& Plutzer, E. (2011). Defeating creationism in the courtroom, but not in the classroom. Science, 331, 404-405.

Bishop, B. A., \& Anderson, C. W. (1990). Student conceptions of natural-selection and its role in evolution. Journal of Research in Science Teaching, 27, 415-427.

Catley, K. M. (2006). Darwin's missing link-a novel paradigm for evolution education. Science Education, 90, 767-783. doi:10.1002/sce.20152.

Catley, K. M., \& Novick, L. R. (2009). Digging deep: exploring college students' knowledge of macroevolutionary time. Journal of Research in Science Teaching, 46, 311-332. doi:10.1002/tea.20273.

Cavallo, A. M. L., \& McCall, D. (2008). Seeing may not mean believing: examining students' understandings and beliefs in evolution. American Biology Teacher, 70, 522-530.

Crisp, M. D., \& Cook, L. G. (2005). Do early branching lineages signify ancestral traits? Trends in Ecology \& Evolution, 20, 122-128.

Cuddeback, G., Wilson, E., Orme, J. G., \& Combs-Orme, T. (2004). Detecting and statistically correcting sample selection bias. Journal of Social Service Research, 30, 19-33. doi:10.1300/J079v30n03_2.

Dagher, Z. R., \& BouJaoude, S. (1997). Scientific views and religious beliefs of college students: the case of biological evolution. Journal of Research in Science Teaching, 34, 429-445.

Darwin, C. (1859). On the origin of species by means of natural selection, or on the preservation of favoured races in the struggle for life. London: Murray.

Demastes-Southerland, S., Good, R. G., \& Peebles, P. (1995). Students' conceptual ecologies and the process of conceptual change in evolution. Science Education, 79, 637-666.

Dobzhansky, T. (1973). Nothing in biology makes sense except in the light of evolution. American Biology Teacher, 35, 125-129.

Dodick, J., \& Orion, N. (2002). Introducing evolution to non-biology majors via the fossil record: a case study from the Israeli high school system. American Biology Teacher, 65, 185-190.

Donovan, S. (2005). Teaching the tree of life: Tree thinking and reasoning about change over deep time. In R. Bybee (Ed.), Evolutionary science and society: educating a new generation (pp. 87-90). Colorado Springs: Biological Sciences Curriculum Study.

Duncan, T., Phillips, T. R., \& Wagner, W. H, Jr. (1980). A comparison of branching diagrams derived by various phenetic and cladistics methods. Systematic Botany, 5, 264-293.

Evarts, S., Krufka, A., Wilson, C. (2006). I'm looking over a white-stripes clover. National Center for Case Study Teaching in Science Case Study Collection. http://sciencecases.lib.buffalo.edu/cs/collection/detail. asp?case_id $=272 \& i d=272$.

Flammer, L. (2007). Mystery of the matching marks or Search for the tell-teale telomere. Evolution and the Nature of Science Institute http://www.indiana.edu/ ensiweb/lessons/mmm.html. Accessed 17 September 2008.

Gendron, R. F. (2000). The classification and evolution of caminalcules. Americal Biology Teacher, 62, 570-576.

Gibson, J. P. (2008). Exaggerated traits and breeding success in widowbirds: A case of sexual selection. National Center for Case Study Teaching in Science. http://sciencecases.lib.buffalo.edu/cs/collection/detail. asp?case_id $=237 \& i d=237$.

Gibson, J. P., Cooper, J. T. (2014). Investigating plant evolution via morphological and molecular phylogenetic analysis. PlantEd Digital Learning Library. http://planted.botany.org/index.php?P=FullRecord\&ID=546.

Goldsmith, D. (2003). The great clade race: presenting cladistic thinking in both biology majors and general science students. American Biology Teacher, 25, 679-682.

Gregory, T. R. (2008). Understanding evolutionary trees. Evolution: Education and Outreach, 1, 121-137.

Gregory, T. R., \& Ellis, C. A. J. (2009). Conceptions of evolution among science graduate students. BioScience, 59, 792-799. doi:10.1525/bio.2009.59.9.10. 
Halverson, K. L. (2010). Using pipe cleaners to bring the tree of life to life. American Biology Teacher, 74, 223-224.

Halverson, K. L. (2011). Improving tree thinking one learnable skill at a time. Evolution: Education and Outreach, 4, 95-106.

Hawley, P. H., Short, S. D., McCune, L. A., Osman, M. R., \& Little, T. D. (2011). What's the matter with Kansas? The development and confirmation of the evolutionary attitudes and literacy survey (EALS). Evolutio: Education and Outreach, 4, 117-132.

Herreid, C. F. (2005). An antipodal mystery. National Center for Case Study Teaching in Science Case Study Collection. http://sciencecases.lib.buffalo. edu/cs/files/antipodal_mystery.pdf. Accessed 25 Aug 2006.

Hobbs, F. C., Johnson, D. J., \& Kearns, K. D. (2013). A deliberate practice approach to teaching phylogenetic analysis. CBE-Life Sciences Education, $12,676-686$.

Hopkins, K. D., \& Stanley, J. C. (1981). Educational and psychological measurement and evaluation (6th ed.). Englewoods Cliffs: Prentice-Hall.

Horvath, T. (2009a). Cross-dressing salmon: Survival of the sneaky. The National Center for Case Study Teaching in Science Case Study Collection. http:// www.sciencecases.org/sneaky_salmon/prelude.asp. Accessed 5 Dec 2009

Horvath, T. (2009b). Not necessarily on purpose: Domestication and speciation in the Canidae family. The National Center for Case Study Teaching in Science Case Study Collection. http://www.sciencecases.org/dog_evolution/prelude.asp. Accessed 5 Dec 2009.

Huck, S. (2008). Reading statistics and research. Boston: Pearson Education.

Johnson, R. L., \& Peeples, E. E. (1987). The role of scientific understanding in college: student acceptance of evolution. American Biology Teacher, 49, 93-98.

Kalinowski, S. T., Leonard, M. J., \& Andrews, T. M. (2010). Nothing in evolution makes sense except in the light of DNA. CBE-Life Sciences Education, 9, 87-97.

Leander, C. A, Huskey, R. J. (2008). Those old Kentucky blues: an interrupted case study. National Center for Case Study Teaching in Science Case Study Collection. http://sciencecases.lib.buffalo.edu/cs/collection/detail. asp?case_id $=208 \& i d=208$. Accessed 5 Feb 2009 .

Linhart, Y. (1997). The teaching of evolution-we need to do better. BioScience, $47,385-391$.

Lloyd-Strovas, J. D., \& Bernal, X. E. (2012). A review of undergraduate evolution education in United States' universities: building a unifying framework. Evolution: Education and Outreach, 5, 453-465. doi:10.1007/ s12052-012-0435-9.

Losos, J. B., Arnold, S. J., Bejerano, G., Brodie III, E. D., Hibbett, D., Hoekstra, H. E., et al. (2013). Evolutionary biology for the 21st century. PLoS Biology, 11, 1-8. e1001466:1-8.

Marx, J. D., \& Cummings, K. (2007). Normalized change. American Journal of Physics, 75, 87-91.

Meir, E., Perry, J., Herron, J. C., \& Kingsolver, J. (2007). College students' misconceptions about evolutionary trees. American Biology Teacher, 69, 71-76.

Meisel, R. P. (2010). Teaching tree thinking to undergraduate biology students. Evolution: Education and Outreach, 3, 621-628.

Mesquite Project Team. (2009). Mesquite: a modular system for evolutionary analysis. http://mesquiteproject.wikispaces.com. Accessed 14 Feb 2009.

Miller, K. R. (2005). Only a theory: evolution and the battle for America's soul. New York: Penguin Press.

Miller, J. D., Scott, E. C., \& Okamoto, J. C. (2006). Public acceptance of evolution. Science, 313, 765-766.

Moore, R. (2008). Creationism in the biology classroom: what do teachers teach and how do they teach it? American Biology Teacher, 70, 79-84.

Moore, R., Brooks, D. C., \& Cotner, S. (2011). The relation of high school biology courses and students' religious beliefs to college students' knowledge of evolution. American Biology Teacher, 73, 222-226.

Moore, R., \& Cotner, S. (2009a). Educational malpractice: The impact of including creationism in high school biology courses. Evolution: Education and Outreach, 2, 95-100.

Moore, R., \& Cotner, S. (2009b). The creationist down the hall: does it matter when teachers teach creationism? BioScience, 29, 429-436.

Moore, R., \& Kraemer, K. (2005). The teaching of evolution and creationism in Minnesota. American Biology Teacher, 67, 457-466.

Nadelson, L. S., \& Southerland, S. A. (2010). Examining the interaction of acceptance and understanding: how does the relationship change with a focus on macroevolution? Evolution: Education and Outreach, 3, 82-88.
Naegle E. (2009). Patterns of thinking about phylogenetic trees: a study of student learning and the potential of tree thinking to improve comprehension of biological concepts. Doctor of Arts Thesis, Idaho State University. Pocatello, ID.

National Academy of Sciences. (1999). Science and creationism. Washington, DC: National Academy Press.

National Academy of Sciences. (2008). Science, evolution, and creationism. Washington, DC: National Academy Press.

National Research Council. (2012). Thinking evolutionarily: evolution education across the life sciences: summary of a convocation. Washington, DC National Academies Press.

Nehm, R. H., Poole, T. M., Lyford, M. E., Hoskins, S. G., Carruth, L., Ewers, B. E., et al. (2009). Does the segregation of evolution in biology textbooks and introductory courses reinforce students' faulty mental models of biology and evolution? Evolution: Education and Outreach, 2, 527-532. doi:10.1007/ s12052-008-0100-5.

Nehm, R. H., \& Reilly, L. (2007). Biology majors'knowledge and misconceptions of natural selection. BioScience, 57, 263-272.

O'Hara, R. J. (1997). Population thinking and tree thinking in systematics. Zoologica Scripta, 26, 323-329.

Perry, J., Meir, E., Herron, J. C., Maruca, S., \& Stal, D. (2008). Evaluating two approaches to helping college students understand evolutionary trees through diagramming tasks. CBE Life Science Education, 7, 193-201.

Rice, N. A. (2010) The Wolfman: a Mendelian monster? The chromosomal basis of heredity. National Center for Case Study Teaching in Science. http://sciencecases.lib.buffalo.edu/cs/collection/detail.asp?case_id=480\&id=480. Accessed 1 Dec 2010.

Rutledge, M. L., \& Mitchell, M. A. (2002). Knowledge structure, acceptance teaching of evolution. American Biology Teacher, 64, 21-28.

Rutledge, M. L., \& Sadler, K. C. (2007). Reliability of the measure of acceptance of the theory of evolution (MATE) instrument with university students. American Biolology Teacher, 69, 332-335.

Rutledge, M. L., \& Warden, M. A. (1999). The development and validation of the measure of acceptance of the theory of evolution instrument. School Sciience and Mathematics, 99, 13-18.

Sinatra, G. M., Brem, S. K., \& Evans, E. M. (2008). Changing minds? Implicagtions of conceptual change for teaching and learning about biological evolution. Evolution: Education and Outreach, 1, 189-195.

Smith, M. U. (2010). Current status of research in teaching and learning evolution: II. Pedagogical issues. Science Education, 19, 539-571.

Smith, J. J., \& Cheruvelil, K. S. (2009). Using inquiry and tree thinking to "march through the animal phyla": teaching introductory comparative biology in an evolutionary context. Evolution: Education and Outreach, 2, 429-444.

Smith, M. U., \& Siegel, H. (2004). Knowing, believing, and understanding: what goals for science education? Science Education, 13, 553-582.

Society of Systematic Biologists. (2001). Support for the teaching of evolution and scope of systematic biology, Society of Systematic Biologists. http:// systbio.org/teachevolution.html. Accessed 1 July 2010.

Sokal, R. R., \& Rohlf, F. J. (2012). Biometry: the principles and practice of statistics in biological research (4th ed.). New York: W. H. Freeman and Co.

Southerland, S. A., \& Sinatra, G. M. (2005). The shifting roles of acceptance and dispositions in understanding biological evolution. In S. Alsop (Ed.), The affective dimensions of cognition: studies from education in the sciences. The Netherlands: Springer.

Southerland, S. A., Sinatra, G. M., \& Matthews, M. R. (2001). Belief, knowledge, and science education. Educational Psychology Review, 13, 325-351.

Sundberg, M. D. (1997). Assessing the effectiveness of an investigative laboratory to confront common misconceptions in life sciences. In AP McNeal and C D'Avanzo, (Eds.), Student-active science: models of innovation in college science teaching. Orlando: Harcourt, Brace and Company.

Theobald, R., \& Freeman, S. (2014). Is it the intervention or the students? Using linear regression to control for student characteristics in undergraduate STEM education research. CBE-Life Sciences Education, 13, 41-48. doi:10.1187/cbe-13-07-0136.

Verhey, S. D. (2005). The effect of engaging prior learning on student attitudes toward creationism and evolution. BioScience, 55, 996-1003.

Yates, T. B, Marek, E. A. (2014). Teachers teaching misconceptions: a study of factors contributing to high school biology students' acquisition of biological evolution-related misconceptions Evolution: Education and Outreach, 7, 7. doi:10.1186/s12052-014-0007-2. Accessed 26 Oct 2014. 